\title{
Organização dos Serviços de Saúde: A Comparação como Contribuição
}

* Escola de Serviço Social da Universidade Federal do Rio de Janeiro, Av. Pasteur, 405, 22290 - Rio de Janeiro - RJ

** Núcleo de Estudos Políticos e Sociais em Saúde Nupes/Ensp/Fiocruz

*** Departamento de Nutrição/UFMT

**** Departamento de Administração e Planejamento em Saúde Ensp/Fiocruz

\author{
Eleonor Minho Conill* \\ Maria Helena Mendonça** \\ Rosângela Alves Pereira R. da Silva*** \\ Virginia Gawryszewski****
}

Procedimento recente na área de saúde, o trabalho discute a comparação como metodologia de análise. As diferentes correntes analiticas - funcionalismo, materialismo-histórico e novas correntes referenciam-se a um método particular de entender o processo saúde-doença. Seus fundamentos filosóficos, sociológicos, conceitos, instrumentos de análise e propostas são apresentados, procedendo-se a uma revisão dos principais trabalhos de autores representativos: Navarro, Terris, Roemer, Fry, lllich e Capra, entre outros.

Sugere-se que a análise comparada pode seguir uma vertente mais operacional, que instrumentaliza a análise de situações concretas em organização de serviços; ou outra, de ordem mais conceitual, que identifica questōes criticas e tendências internacionais na área de saúde. $O$ debate mais recente busca a superação destas dicotomias em direção ao avanço na produção do conhecimento e seu reflexo na organização de serviços de sauide.

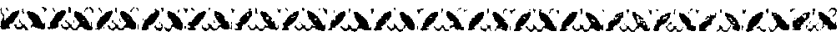

\section{INTRODUÇÃO: HÁ ALGO DE NOVO NO FRONT?}

Estudos sobre organização de serviços são cada vez mais freqüentes em nosso meio. A produção acadêmica e científica em planejamento de saúde vinha se concentrando antes na análise das políticas de saúde, em aspectos gerais da implementação do processo de Reforma Sanitária e nos desenvolvimentos teóricos mais recentes da área, tais como o planejamento estratégico-situacional. As questões diretamente relacionadas à organização e à própria avaliação de serviços vinham sendo objeto de um tratamento menos expressivo. Os dois últimos Congressos da Associação Brasi- 
leira de Saúde Coletiva - Abrasco $(1986,1989)$ demonstram que tem havido uma preocupação crescente com o tema, tanto pelo aumento quantitativo dos trabalhos quanto por sua presença nos cursos e comunicaçōes coordenadas.

Este trabalho discute a comparação no estudo da organização de serviços e de sistemas de saúde. Pretende ser uma contribuição metodológica para a análise das transformações que vêm ocorrendo neste âmbito, no Brasil, nesta última década. Comparar é buscar semelhanças, diferenças ou relações entre fenômenos que podem ser contemporâneos ou não, que ocorram em espaços distintos ou não, tendo em vista conhecer determinações, causalidades e inter-relações.

A utilização desta metodologia lança mão, constantemente, de conhecimentos de várias áreas, desde as ciências sociais, a economia, a política, passando pela epidemiologia. Seu uso neste campo é relativamente novo, iniciandose na década de 50, com estudos essencialmente descritivos (Desroisiers, 1980).

Alguns problemas de ordem conceitual e metodológica têm sido apontados na análise comparativa: concepção de saúde, análise do setor e de suas determinações, discriminação entre os aspectos referentes aos sistemas e as políticas de saúde e métodos e técnicas de avaliação.

Qual seria, então, a especificidade, características e conteúdo dos estudos dessa ordem? Este texto pretende responder esta questão através da análise de trabalhos de autores representativos na área. Não se limita a uma revisão bibliográfica já que busca apontar o essencial da contribuição de cada autor no processo cumulativo de construção do conhecimento neste campo.

Para fins de estudo, os trabalhos foram classificados em três correntes: funcionalismo, materialismo-histórico e novas correntes. Escapa ao nosso objeto aprofundar a discussão sobre os pressupostos teóricos mais gerais que caracterizam estas correntes. Para tanto, tomamos como referência a discussão feita por Conill (1982), Garcia (1983) e Minayo (1989). As caracteristicas que consideramos mais importantes estão sintetizadas no Quadro I. Temos, porém, clareza dos riscos de reducionismo e das limitações decorrentes de qualquer classificação. Mas, vejamos se há algo de novo no front. 


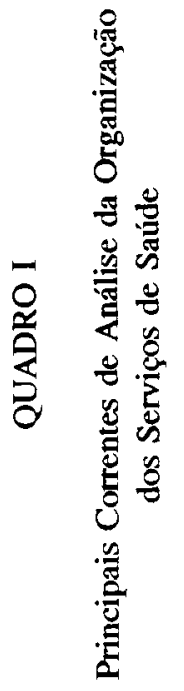

\begin{tabular}{|c|c|c|c|}
\hline 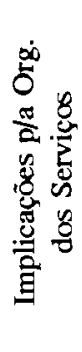 & 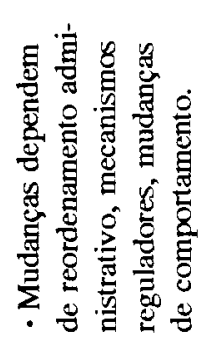 & 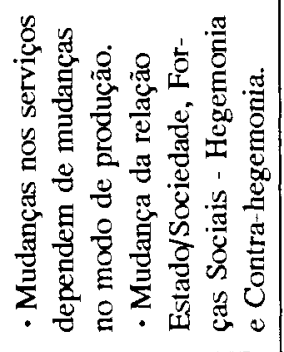 & 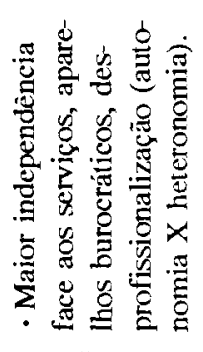 \\
\hline 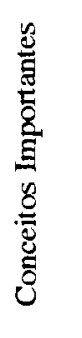 & 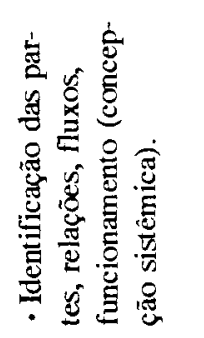 & 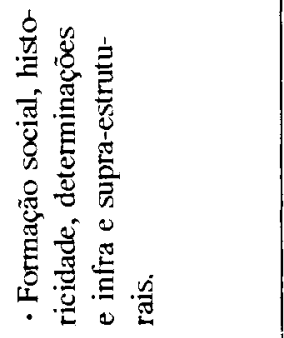 & 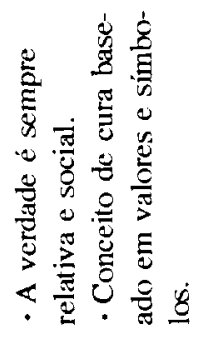 \\
\hline 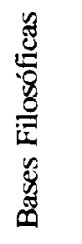 & 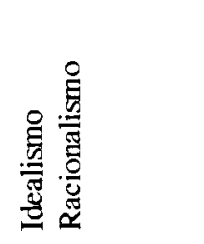 & $\frac{\pi}{\frac{\pi}{2}}$ & 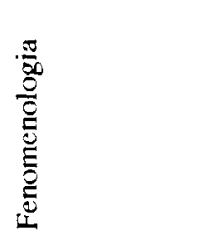 \\
\hline 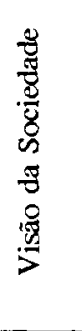 & 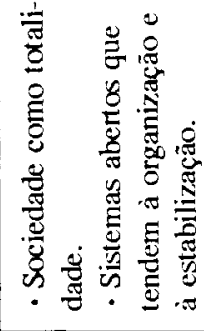 & 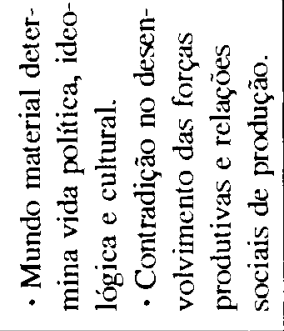 & 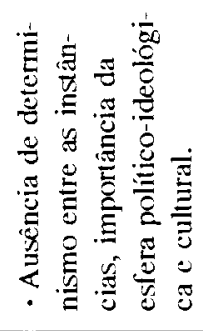 \\
\hline 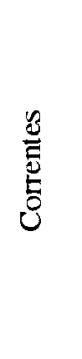 & 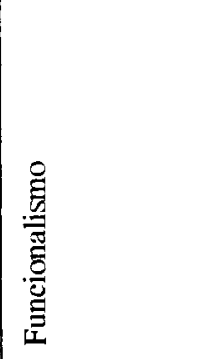 & 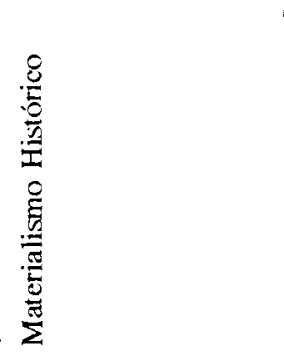 & 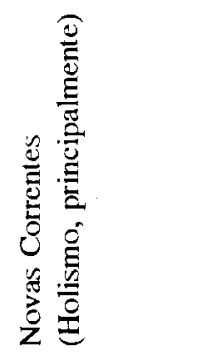 \\
\hline
\end{tabular}




\section{A ORIENTAÇÃC FUNCIONALISTA NA ANÁLISE COMPARATIVA: A BUSCA DA EXPLICAÇÃO OPERATIVA}

Nesta abordagem, a sociedade é entendida como uma totalidade, através do conceito de sistema social no qual a integração entre as partes leva a um estado de funcionalidade e ordem. É a partir do conceito de doença como desvio funcional que se considera a necessidade da existência de sistemas e serviços de saúde para que as instituições e os indivíduos mantenham-se em estado de ordenamento e cumpram seus papeis sociais.

Predominam neste grupo os trabalhos descritivos que visam classificações e o estabelecimento de indicadores que expliquem a estrutura e o funcionamento de diversos sistemas oficiais de atenção à saúde, de forma a compará-los. No âmbito da explicação, a conformação dos sistemas é resultado de fatores tais como a geografia, as características demográficas, o nível de desenvolvimento econômico, as decisões políticas, a história e a cultura de cada país. A estruturação dos serviços dependeria de ordenamento administrativo, do estabelecimento de mecanismos reguladores por parte do Estado e de mudanças comportamentais nos principais atores envolvidos (produtores e usuários). $\mathrm{O}$ sistema de saúde deve, no entanto, responder a objetivos comuns e a uma coordenação geral que permita a correta interação entre as partes.

As contribuições da abordagem funcionalista podem ser resumidas em três vertentes: uma que avança nas proposições metodológicas, uma que compara os sistemas a partir de elementos de análise restritos e outra que utiliza elementos de análise mais ampliados. ${ }^{1}$ Esta divisão baseia-se na ênfase percebida nos estudos, embora possa haver superposição. O Quadro II reagrupa os autores e os principais elementos de sua produção teórica.

Uma contribuição importante desta corrente de pensamento é a polêmica em torno da convergência entre os diversos sistemas de saúde das sociedades industriais, dadas certas características estruturais do processo de industrialização, independentemente de suas diferenças históricas e culturais (Field, 1973). Sugerem-se parâmetros de comparação para medir o crescimento e a complexidade desses sistemas em sua dinâmica organizacional e funcional. Frenk e Donabedian (1987) recolocam a questão da convergência
(1) A classificação restrita ou ampliada diz respeito à ênfase em categorias de análise setoriais ou macrossociais. 


\section{ANÁLISE}

QUADRO II

Principais Autores Funcionalistas com Influência na Abordagem Comparativa

\begin{tabular}{|c|c|c|c|}
\hline Autores & $\begin{array}{l}\text { Contribuição Metodológica } \\
\text { p/Análise dos Sistemas de } \\
\text { Saúde }\end{array}$ & $\begin{array}{c}\text { Elementos de Análise } \\
\text { Restritos }\end{array}$ & $\begin{array}{l}\text { Elementos de Análise } \\
\text { Ampliados }\end{array}$ \\
\hline Fry (1969) & $\begin{array}{l}\text { - Estudos iniciais em análise } \\
\text { comparada. }\end{array}$ & $\begin{array}{l}\text { - Compara estruturas e } \\
\text { funcionamento dos } \\
\text { sistemas (EUA, URSS, } \\
\text { Reino Unido). }\end{array}$ & \\
\hline Field (1973) & $\begin{array}{l}\text { - Comparação como método } \\
\text { para visualizar um sistema. } \\
\text { - Define sistema de saúde e } \\
\text { seus elementos constitu- } \\
\text { tivos, suporte estrutural e } \\
\text { atividades. } \\
\text { - Toeria da convergência. }\end{array}$ & & \\
\hline $\begin{array}{l}\text { Cochrane et alii } \\
\text { (1978), Miguel } \\
\text { (1978) }\end{array}$ & - Comparação de resultados. & & $\begin{array}{l}\text { - Indicadores de aten- } \\
\text { ção médica; indicado- } \\
\text { res sociais; indicadores } \\
\text { epidemiológicos. }\end{array}$ \\
\hline Stephen (1979) & & $\begin{array}{l}\text { - Atenção primária em } \\
\text { diversos paises. }\end{array}$ & \\
\hline Mechanic (1979) & $\begin{array}{l}\text { - Parte das inter-relações } \\
\text { dos sistemas econômico e } \\
\text { político. }\end{array}$ & $\begin{array}{l}\text { - Comportamento do } \\
\text { individuo face a saúde. } \\
\text { - Comportamento do } \\
\text { profissional. } \\
\text { - Ação do Estado. }\end{array}$ & \\
\hline $\begin{array}{l}\text { Roemer }(1980 \text {, } \\
82,84)\end{array}$ & $\begin{array}{l}\text { - Constrói tipologia dos } \\
\text { sistemas atuais de saúde. } \\
\text { - Sistematiza estratégias de } \\
\text { reorientação dos sistemas. } \\
\text { - Comparação como forma } \\
\text { de conhecer o desenvolvi- } \\
\text { mento, a estrutura e a dinâ- } \\
\text { mica dos diversos sistemas } \\
\text { de atenção à saúde. }\end{array}$ & $\begin{array}{l}\text { - Desenvolvimento de } \\
\text { recursos de saúde, } \\
\text { alocação de recursos, } \\
\text { prestação de serviços, } \\
\text { financiamento e gerên- } \\
\text { cia. } \\
\text { - ética médica, edu- } \\
\text { cação médica e prática } \\
\text { privada. }\end{array}$ & $\begin{array}{l}\text { - Indicadores sócio- } \\
\text {-económicos, como } \\
\text { PNB/per-capita. } \\
\text { - Caracteristicas sócio- } \\
\text {-políticas do sistema } \\
\text { relativas à noçāo de } \\
\text { saúde. }\end{array}$ \\
\hline Desrosiers (1987) & $\begin{array}{l}\text { - Parte do estudo da evo- } \\
\text { lução dos recursos; do qua- } \\
\text { dro juridico-institucional, da } \\
\text { organização e funcionamen- } \\
\text { to em três paises } \\
\text { (Canadá, URSS e EUA) }\end{array}$ & $\begin{array}{l}\text { - Comparação dos } \\
\text { serviços por áreas de } \\
\text { interesse de cada país; } \\
\text { (atenção ao idoso, saú- } \\
\text { de do trabalhador, re- } \\
\text { formas sanitárias). } \\
\text { - Estudo de formação e } \\
\text { organização da pro- } \\
\text { fissão médica. }\end{array}$ & $\begin{array}{l}\text { - Indicadores demográ- } \\
\text { ficos; epidemiológicos; } \\
\text { sócio-econômicos; a } \\
\text { política social e aspec- } \\
\text { tos culturais. }\end{array}$ \\
\hline $\begin{array}{l}\text { Frenk e } \\
\text { Donabedian } \\
\text { (1978) }\end{array}$ & $\begin{array}{l}\text { - Crítica à teoria da con- } \\
\text { vergència. } \\
\text { - Classificação dos sistemas } \\
\text { segundo a relação Esta- } \\
\text { do/Sociedade }\end{array}$ & & $\begin{array}{l}\text { - Intervenção do Estado } \\
\text { em relação aos produ- } \\
\text { tores e consumidores } \\
\text { de saúde. }\end{array}$ \\
\hline
\end{tabular}


entre os diversos sistemas de saúde determinada pelo avanço da industrialização e da urbanização, pelas características da economia médica mundial e pela difusão de uma ideologia modernizadora. Mas chamam atenção para o fato de que também existiria divergência determinada pelas características do mercado, pelo sistema de interesses (corporações) e pelo grau de legitimação e normas em relação à propriedade privada.

A partir da forma de intervenção do Estado e das suas relações com produtores e usuários, estes autores propōem uma classificação dos sistemas de saúde, apontando algumas tendências no seu desenvolvimento.

Milton Roemer destaca-se por sua produção abrangente, pioneira e constante. Seu livro "Perspectiva mundial de los sistemas de salud" (1980) constitui, provavelmente, o conjunto descritivo mais completo sobre o tema. Mesmo tratando de questões específicas em sua obra, tais como: ética, educação médica (1982) e prática privada (1984), a abordagem de Roemer é comparativa, situando as questões no plano internacional e cotejando várias realidades.

Num trabalho mais recente (Klecskowski et alii, 1984), define-se um modelo de sistema de saúde composto por infra-estrututura $^{2}$ ou elementos organizativos, funções e produtos. Constrói-se uma tipologia dos sistemas atuais em função do PNB (paises ricos, em transição, pobres) e do grau de organização de cada sistema (pouco, moderadamente e muito organizados). Segundo os autores, esta tipologia seria útil para sistematizar estratégias de reorientação coerentes com o objetivo de "Saúde Para Todos até o ano 2000 ", a famosa meta SPT/2000 (OMS, 1978).

A abordagem funcionalista contribuiu largamente para as propostas de modificação dos sistemas de saúde no interior dos setores de planejamento dos sistemas de saúde, tanto dos países em desenvolvimento como dos países industrializados. Na década de 70 , os países em desenvólvimento enfrentaram suas dificuldades estruturais de organização de um sistema de saúde dirigindo seus estudos para propostas inovadoras que culminaram com a idéia da atenção primária e o objetivo da "Saúde Para Todos", através da revisão de suas formas organizacionais (Djukanovic, 1975; Hetzel, 1978; Lathem, 1970). A proposta mais atualizada neste sentido é a dos Sistemas Locais de Saúde/SILOS, que abarca três dimensões: a questão da população, do espaço e dos recursos, destacando-se a importância de uma gestão Cadernos de Saúde Pública, RJ, 7(3): 328-346, jul/set, 1991
(2) Seriam cinco os componentes da infra-estrutura: desenvolvimento de recursos, disposição ordenada desses recursos, prestação de serviços, apoio econômico e gerência. 
única e da inserção dos serviços locais num sistema descentralizado (OPS, 1988).

Examinamos, nesta parte, um conjunto amplo e diversificado de trabalhos que, como se pode observar, prioriza, em última instância, a operação dos servidores.

\section{A ABORDAGEM MATERIALISTA-HISTÓRICA NA ANÁLISE COMPARATIVA: A QUASE AUSÊNCIA DE ESQUEMAS E TIPOLOGIAS}

Segundo Waitzkin (1978), os estudos marxistas na comparação dos sistemas de saúde têm-se concentrado sobre as relações do imperialismo com a assistência à saúde, a organização dos serviços nos países em transição para o socialismo e as contradições das reformas capitalistas.

Navarro $(1976,1977,1983)$ é, provavelmente, o autor contemporâneo mais representativo da aplicação do paradigma marxista na área de saúde. $O$ objeto de seu estudo não é a comparação em si, ela aparece como elemento intrínseco à utilização do método materialista-histórico e dialético no entendimento do processo saúde-doença e da organização dos serviços.

Para entender a subordinação do setor saúde às relações sociais de produção, Navarro considera ser necessário inseri-lo numa totalidade social concreta historicamente determinada, o que pressupõe a utilização como categorias essenciais para a análise a divisão internacional do trabalho, os padrões de acumulação, o imperialismo e as classes sociais.

Navarro trata questões gerais como a natureza da medicina no capitalismo, classe, poder político e cuidados de saúde (1976), a natureza do imperialismo e suas implicações na saúde e na medicina (1983) e as relações entre trabalho, ciência e ideologia no caso da medicina (1983).

Desenvolve, também, os seguintes temas específicos: 1 - as causas e as conseqüências do subdesenvolvimento da América Latina para as condições de saúde e para a distribuição dos recursos nestes países (1983);

2 - as tentativas e os bloqueios a mudanças deste padrão, através da análise do caso do Chile de Allende (1976);

3 - o subdesenvolvimento da saúde no mundo capitalista desenvolvido, através do estudo das condições e dos serviços de saúde da população rural e da classe trabalhadora dos Estados Unidos (1976); 
4 - a reprodução no interior das instituições de saúde neste país, do caráter monopolista, corporativo e classista da sociedade norte-americana (1976).

Critica, assim, as teorias do desenvolvimento ${ }^{3}$, alertando para 0 fato de que o imperialismo pode estar presente também nas comparações. Uma vez que a problemática do setor saúde apenas reflete a situação de subdesenvolvimento gerada e mantida pelos mecanismos necessários à reprodução do capital nos países desenvolvidos. Assinala a ênfase empirista e descritiva dos trabalhos sobre serviços de saúde relativos ao mundo subdesenvolvido, que omitiriam propositadamente as causas do subdesenvolvimento, atendo-se à falácia da falta de recursos, tecnologia e educação. Segundo sua expressão, são os especialistas em árvores que não conseguem ver o bosque (Navarro, 1983) e para os quais, o modelo adequado seria o do mundo desenvolvido. Assim, num grande número de referências, os indicadores dos países subdesenvolvidos (por exemplo, leitos por habitantes) são comparados com os dos países desenvolvidos, aceitando-se como premissa que estes indicadores possam ser usados como modelos e objetivos a serem alcançados pelos primeiros.

Terris (1980) não utiliza necessariamente categorias marxistas clássicas, mas correlaciona a saúde com a estrutura econômica e política das sociedades, atribuindo historicidade às suas transformações. Desde a metade da década de 70 vem discutindo as tendências e perspectivas dos diversos sistemas de saúde, salientando a sua preocupação com a possibilidade de transformação do sistema de atenção médica dos Estados Unidos.

Seus estudos apontam para a existência de três sistemas mundiais de atenção médica: assistência pública, seguro-saúde e serviço nacional, os quais teriam uma correspondência com os sistemas econômicos dominantes, pré-capitalistas e socialistas, respectivamente.

O processo social continuo de perpetuação de um sistema ou de transição para um outro pode levar à coexistência dos modelos referidos numa mesma sociedade. Terris examina como estas transições vão se dando e sua racionalidade em atender às demandas por serviços que proporcionem atenção a toda a população, de forma integral e eficaz.

Adotando uma abordagem comparativa, percebe como tendência predominante uma evolução para o modelo de serviço nacional de saúde, a partir de reformas sociais nos
(3) Refere-se, sobretudo, a Rostow (1962), para o qual o desenvolvimento se daria em cinco etapas, universais e aplicáveis a qualquer país. 
(4) A política social é avaliada em relação a seis aspectos: prioridade e recursos, controle, equilibrio da provisão entre Estado, mercado, local de trabalho e comunidade, relaçōes entre usuários, produtores e administradores, mecanismos de racionalização e divisão sexual do trabalho. países capitalistas. Descreve, então, duas formas de transição observáveis na constituição dos sistemas de saúde, uma a partir do sistema seguro-doença e outra a partir da assistência pública. Assinala que, para além da adoção de alguns métodos reformistas para expandir a cobertura e definir uma nova intervenção do Estado, a questão básica é política, no sentido de resolver o conflito entre a tendência de preservar os interesses privados em geral e a tendência de defender os interesses coletivos enquanto uma ação estatal planejada.

Como sua preocupação se refere especialmente ao sistema de saúde dos Estados Unidos, aborda, numa seqüência recente de editoriais (Terris, 1986, 1987), a confusão semântica que estaria ocorrendo quanto ao uso dos conceitos de seguro e sistema nacional de saúde. Essa discussão é, sem dúvida, interessante para a metodologia comparativa e para a atual conjuntura brasileira.

Tal confusão representaria, na realidade, a expressão do confronto de interesses diversos na definição da política de saúde naquele país. Por um lado, defende-se a criação de um serviço nacional de saúde como resposta à ineficácia e ao custo elevado dos serviços oferecidos. Por outro lado, pressupõe-se a existência de um seguro nacional de saúde, favorecendo as pressões das seguradoras e de certas forças políticas corporativas a fim de que o Estado subvencione os seguros privados.

Finalmente, dentro do materialismo histórico, a abordagem de Deacon (1983) e San Martin (1985) são, no mínimo, inovadoras. Deacon incorpora categorias feministas, partindo do princípio de que as mudanças das relações sociais no cotidiano são fundamentais para transformações sociais. A sociedade socialista deveria terminar com todas as formas de dominação, inclusive aquelas relativas a cor, sexo e idade. Reflete sobre o conteúdo das políticas sociais de tipo socialista e comunista, estabelecendo uma $\operatorname{grade}^{4}$, aplicando-a em várias sociedades onde ocorreram transformações sociais (Rússia, Hungria, Polônia, China, Cuba, Moçambique). Além disto, compara indicadores de recursos e de resultados destes países com outros do mundo capitalista.

San Martin (1985) caracteriza-se por agregar à abordagem materialista-histórica, uma perspectiva ecológica, bem antes desta discussão assumir o grau de difusão atual. Estabelece um modelo complexo de análise que denomina sistema social, histórico e ecológico da saúde-doença nas 
sociedades humanas. Segundo ele: $A$ saúde, como a doença, não emana apenas do patrimônio genético, mas depende de fatores ambientais e sociais complexos com os quais devemos, necessariamente para viver, manter uma relação ecológica compativel com a sobrevivência de nossa espécie. Pois, isto é o que ocorre na natureza a todas as espécies vivas, sejam animais ou vegetais. Assim, a noção do individuo como um ser independente na Terra é um mal-entendido dos mais perigosos para o nosso futuro como espécie. Não basta para conhecermo-nos, definirmo-nos como homo sapiens e como seres humanos para em seguida colocarmo- nos numa cúspide isolada da evolução orgânica. Isto significa desconhecer a unidade da vida na Terra, desconhecer a comunidade de todos os seres vivos, animais $e$ vegetais, unidos todos através de ecossistemas num extraordinário equilibrio trófico que, apesar da constante variação, permite a vida de todos (1979).

É exatamente a relação do homem com a natureza uma das questões que as novas correntes de análise, que veremos a seguir, desenvolvem. Tal como no materialismo-histórico, o fio condutor não é a estabilidade da ordem social vigente, mas as contradições que levam a rupturas e mudanças. No entanto, são redefinidos os motores e os atores destas mudanças.

NOVAS CORRENTES DE ANÁLISE: PARA ALÉM DAS REVOLUÇÕES OU REFORMAS NOS SERVIÇOS -
A BUSCA DE UMA NOVA POSTURA FACE À VIDA E À SAỨDE

Uma outra possibilidade de análise das questões de saúde e de organização dos serviços situa-se no âmbito de uma crítica à moderna medicina cientifica ocidental e do desenvolvimento de um paradigma holístico.

Para Illich (1975), a crítica à medicina moderna faz parte de um questionamento mais amplo feito à industrialização e suas consequiências. $O$ efeito da medicina através da iatrogênese clínica, social e estrutural constituiria a principal epidemia de nossa época. Considera a medicina um produto das sociedades industrializadas que, assim como as demais instituições nestas sociedades, tenderiam a ser organizações burocráticas, hierarquizadas e autoritárias.

A prática médica gerada no seio das contradições da sociedade industrial, faz nascer novas e profundas contradiçōes, entre as quais o autor aponta: a) o controle instiCadernos de Saúde Pública, RJ, 7(3): 328-346, jul/set, 1991 
(5) De acordo com Gorz (1987), a produção autônoma diz respeito à produção por parte da comunidade de pelo menos uma parcela dos bens e serviços que consome, sem que haja vinculação cơm o processo de produção capitalista. A produção heterônoma relaciona-se com a produção de bens e serviços socialmente necessários e que não podem ser realizados com a mesma eficácia pelas atividades autônomas. A primeira se define na "esfera da liberdade" e a segunda na "esfera da necessidade". tucional da população por parte da medicina como forma de alienar do indivíduo o domínio sobre seu trabalho, lazer, corpo, alimentação, tornando-o socialmente impotente; b) a mercantilização das coisas, palavras e gestos relacionados com o ato médico, aliada à medicalização e ao controle social, resultam no que ele chama de "medicalização do orçamento" - quanto mais se gasta com "saúde", mais a sociedade e os individuos tornam-se doentes.

Utiliza o exemplo da prática médica para aplicar sua teoria da contraprodutividade do sistema industrial devido à ausência de sinergismo entre produção autônoma e heterônoma ${ }^{5}$. Na medida em que esta prática se torna hegemônica, diminui o grau de autonomia dos indivíduos e dos grupos sociais sobre o corpo e sobre os processos relativos à vida, como nascimento, prazer, dor e morte.

A medicalização extrapola, assim, as fronteiras da doença e se estende aos sadios, já que há necessidade de se fazer freqüentes exames preventivos ou exames de saúde, como por exemplo o check-up. Ou, quando se estabelecem condutas e rotinas especializadas para as diversas fases da vida, caracterizando o domínio da "ciência" sobre os processos biológicos e psicológicos dos indivíduos. Assim, temos a atenção aos recém-nascidos, às gestantes, aos idosos, aos pré-escolares, elaboram-se parâmetros de comportamento sexual, de práticas alimentares, de condicionamento físico etc.

Fundamenta seus argumentos considerando países como a França, Estados Unidos, Inglaterra, União Soviética, China, Brasil e México, adotando uma abordagem comparativa e aproximando-se de autores que sustentam a "teoria da convergência", por privilegiar a industrialização como categoria explicativa.

Capra (1982) assinala as crises que estariam ocorrendo em várias áreas: economia, psicologia e medicina, entre outras, como conseqüência de uma visão cartesiana de mundo e de uma concepção mecanicista da vida, fortemente influenciadas pela física newtoniana. Uma transformação estaria em curso, rumo ao que ele chama de "ponto de mutação". A emergência de contrapropostas ao modelo biomédico clássico levariam ao surgimento da perspectiva holística na área da saúde, na qual a compreensão da realidade é feita a partir de totalidades integradas cujas propriedades não podem ser reduzidas a unidades menores. $O$ organismo humano é visto como um sistema vivo cujos 
componentes estão todos interligados e interdependentes, sistema que é parte integrante de sistemas maiores, com os quais estabelece uma interação e sintonia contínuas.

Para o desenvolvimento de uma abordagem holística em saúde, que seja compatível com a nova física e com a concepção sistêmica dos organismos vivos, Capra (1982) sugere estudos transculturais, com destaque para a análise comparativa de sistemas médicos tradicionais. Segundo ele, o moderno pensamento científico - em fisica, biologia e psicologia - está conduzindo a uma visão da realidade que se aproxima muito da visão dos místicos e de numerosas culturas tradicionais, em que o conhecimento da mente $e$ do corpo humanos e a prática de métodos de cura são partes integrantes da filosofia natural e da disciplina espiritual (1982, p.299). Propõe, por exemplo, o estudo dos rituais xamânicos, da medicina tradicional chinesa e da prática médica do Japão contemporâneo. A análise desta última seria de interesse para identificar formas que permitam a combinação de técnicas orientais e ocidentais e a adoção de uma atitude mais equilibrada na relação do conhecimento racional com o intuitivo.

As abordagens citadas são representativas de um conjunto heterogêneo de propostas que se expressam pela valorização da homeopatia, das práticas orientais, de uma gama variada de terapias corporais, da naturopatia, da fitoterapia e das práticas médicas de auto cuidado. Estas novas tendências se articulam na sociedade enquanto movimentos sociais com outros movimentos, tais como o feminista e o ecológico.

Para Melucci (1978), os novos movimentos sociais lutariam não apenas pela reapropriação da estrutura material de produção mas, também, pelo controle coletivo do desenvolvimento. Isto significaria a reaproximação do tempo, do espaço e das relaçōes dos indivíduos na sua existência cotidiana.

Estes movimentos colocariam, portanto, o problema de controle dos recursos coletivos (natureza, corpo, relaçōes interpessoais) em termos diretamente culturais.

O sistema industrial, segundo Gorz (1987), subordina o individuo à tecnocracia, à burocracia e ao poder do capital. A defesa da identidade e dos espaços individuais na busca de um reequilibrio entre os setores autônomo e heterônomo da sociedade e de mudança nas relações interpessoais conteriam os elementos da transformação social e da liberação do indivíduo.

Cadernos de Saude Pública, RJ, 7(3): 328-346, jul/set, 1991 
Nos países avançados, estas bandeiras, potencialmente revolucionárias, não estariam mais com a classe operária. Pertenceriam aos "marginalizados" e desempregados do sistema, os quais Gorz denomina "neoproletariado pós-industrial ou a não-classe dos não-trabalhadores" (Gorz, 1987, p. 16). No que diz respeito à saúde, propõe que se deixe ao setor heterônomo - representado pelos serviços - os tratamentos complexos que exijam a utilização de tecnologia. Os problemas simples, que constituem a grande maioria dos casos, seriam tratados em casa, com a ajuda de familiares, amigos, vizinhos, enfim, no âmbito do setor autônomo.

Estas propostas constituem, indubitavelmente, novidade no front da saúde, no mínimo pelas discussões, debates e interrogações que suscitam (Berliner, 1980; Mckee, 1988).

\section{CONSIDERAÇÕES FINAIS}

Nestes tempos de crises, reformas, transformações e transições, refletir sobre o que já foi ou está sendo feito, pode representar a possibilidade de encontrar o novo.

Pela singularidade do conteúdo das práticas em saúde, este campo tem se constituído num locus privilegiado de expressão da crise do pensamento racional ocidental (Caillé, 1986), o que deve ser, no mínimo, melhor investigado. A comparação pode ser um valioso método de repensar as concep̧̧ões, os serviços e a prática.

Diferenças existem, são dadas pelas particularidades de cada processo, pela interação dinânica das características políticas, geográficas, sociais e culturais. Comparar não se resume a estabelecer tipologias e nem se dedica a preconizar a cópia ou a transferência das experiências. Trata-se de encontrar referências para a busca de novos caminhos (Bartos, 1988).

Neste trabalho, a distinção entre as três vertentes de análise é um recurso didático que possibilita visualizar as diferentes maneiras com que o tema - organização de serviços de saúde - tem sido tratado.

Conforme assinalado na introdução, essa classificação não é nova já tendo sido utilizada anteriormente por nós (Conill, 1982), bem como em sociologia da saúde (Garcia, 1983). O que o texto busca é sistematizar também dessa maneira o uso do comparativo.

Através da abordagem funcionalista os fenômenos são reconhecidos em sua regularidade e homogeneidade. Por 
meio das abordagens materialista e holistica, os fenômenos são vistos sob uma perspectiva mais dialética, resultantes da interação entre forças, interesses, valores e ideologias. Sob estas visões, procura-se identificar alternativas de mudanças, no plano infra-estrutural ou supra-estrutural.

Pode-se ver, também, que estas três correntes não são excludentes, muito pelo contrário, a superação da virtual divisão proporciona os elementos para um salto qualitativo na produção do conhecimento.

Este artigo está longe de esgotar o assunto, uma vez que muitos trabalhos de relevância deixaram de ser citados, entre eles, o de Elling (1982) e o de Kervasdoué et alii (1984). Sente-se falta, principalmente, de estudos mais voltados para a problemática latino-americana. A realização e o conteúdo do Seminário sobre Saúde e Políticas Sociais na América Latina (Nupes-Fiocruz, 1990), ainda que situados no plano da análise macrossocial das políticas, demonstraram uma preocupação neste sentido. Neste Seminário foram discutidas as situações do Chile, México, Equador, Colômbia, Argentina e Brasil, sendo importante que sejam desenvolvidas as análises aí surgidas, por exemplo, as implicações da hipótese da heterogeneidade estrutural como categoria explicativa (Possas, 1989, p. 151) na organização dos serviços de saúde.

A maior contribuição deste texto é certamente no plano teórico metodológico, pois, afinal, se há algo de novo no front, é o consenso cada vez maior quanto à crise e à necessidade de reavaliação dos paradigmas até então utilizados. Vislumbra-se a possibilidade de superação das dualidades, buscando-se opções não-reducionistas que caracterizam o isolamento numa ou noutra corrente.

A superação das dificuldades pode se dar pela incorporação dos vários elementos das diversas correntes num processo sintético (e, portanto, dialético) de incorporação das divergências. Neste processo, o olhar das novas correntes já abriu caminho, não deixando de ver a determinação econômica e nem a necessidade de funcionalidade, considerando-se sempre os diversos planos particulares de análise.

Não se está defendendo um ecletismo simplista, que não considera níveis de explicação nem faça referência à totalidade social. Trata-se de discutir a aplicação de cada categoria no momento adequado e de repensar o significado das novas correntes, dos chamados novos movimentos so- 
ciais, na particularidade da organização dos serviços na América Latina e no Brasil.

Assim, se no interior destas correntes a atenção à saúde deve estar centrada na reapropriação individual do tempo, do trabalho e do próprio corpo, é fundamental também repensar o papel dos serviços neste processo de recuperação do indivíduo e de resgate da autonomia. Isto incluiria rever até que ponto princípios reformadores como a extensão da cobertura pela assistência médica não implicaria, de fato, dar passos crescentes em direção à tutela técnico-burocrática impeditiva da criação de valores de uso (Illich, 1984). Portanto, para além da necessidade de garantir conquistas básicas e inegáveis face às necessidades individuais e coletivas de saúde, convém não perder de vista a complexidade destas questões.

Ao se refletir sobre o sistema de saúde no Brasil, na busca de caminhos para o seu aperfeiçoamento, deve-se ter em conta as contribuições e os limites da análise comparada utilizada por cada uma destas abordagens. É preciso desenvolver uma metodologia que supere a tendência fragmentadora do funcionalismo e a ortodoxia do materialismo-histórico, redefinindo as categorias e os indicadores a serem comparados, atentando-se para que a valorização do indivi-duo não obscureça o papel das estruturas sociais da deter-minação dos fenômenos de saúde-doença.

Assim, o que ainda há de novo no front é o esforço teórico-metodológico para superação das dualidades, das polarizações e das dicotomias que tradicionalmente têm marcado a produção do conhecimento na saúde coletiva e em outros campos: entre o econômico e o político-cultural, entre o biológico e o social, entre corpo e mente. Qualquer que seja a metodologia, comparada ou não, é o trabalho integrador e artístico no plano epistemológico, aliado à ruptura das fronteiras da área, que nos permitirá avanços na construção de um novo paradigma, tarefa que transcende o objetivo deste trabalho.

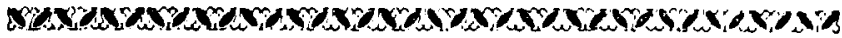

This article discusses about a recent procedure in health care studies, the comparison as a methodology of analysis. The different analytical currents refer to a particular method of understanding health-disease process. They are: functionalism, the historical- 
-materialism and the new currents. Their phylosophical and sociological basis, concepts, analysis instruments and purposes are showed here by a review of the principal works from representative authors as Navarro, Terris, Roemer, Fry, Illich, Capra and others. The paper suggests that comparative analysis can take two directions: the first is a operational approach for analysing the concrete situations of health's service organization, the second, a more conceptual one, aimed at identifying critical questions and international tendencies in health's systems. The recent discussion search for the overcoming of these dichotomies toward the progress of the production of knowledge and its efects in health's services organization.

\section{REFERÊNCIAS BIBLIOGRÁFICAS}

ASSOCIAÇÃO BRASILEIRA DE PÓS-GRADUAÇÃO EM SAÚDE COLETIVA - 1 Congresso Brasileiro de Saúde Coletiva, Rio de Janeiro, 22 a 26 de setembro de 1986, Programa, pp. 89, 103, 107.

ASSOCIAÇÃO BRASILEIRA DE PÓS-GRADUAÇÃO EM SAÚDE COLETIVA/ASSOCIAÇÃO PAULISTA DE SAÚDE PÚBLICA - 20 Congresso Brasileiro de Saúde Coletiva/3Congresso Paulista de Saúde Pública, S. Paulo, 3 a 7 de julho de 1989, Programa, 118p.

BARROS, Eugenio O. M. de - Comentário apresentado na disciplina "Análise comparada da organização de serviços de saúde", ministrada no Curso de Pós-Graduação em Saúde Pública/Mestrado e Doutorado da Escola Nacional de.Saúde Pública/Fiocruz, Rio de Janeiro, 20 semestre de 1988.

BERLINER, H. \& SALOMON, J. W. - The holistic alternative to scientific medicine, history and analysis, Int. J. Health Serv.1980: 133-137.

CAILLÉ, A. Splendeurs et miseres des sciences sociales, Genève: Droz, 1986, 411p.

CAPRA, F. O ponto de mutação, S. Paulo: Cultrix, 1982.

COCHRANE, A.; LEGER, A.; MOORE, F. - "Entradas" de atención de salud y "salidas" de mortalidad en los paises desarrollados in: El desafío de la Epidemiología, problemas e lecturas selecionadas, Washington: Organización Panamericana de la Salud, 1988, pp. 1015-1022, reproduzido do Journal of Epidemiology and Community Health 32:200-205, 1978.

CONILL, E. - Les implications de la santé communautaire en tant que nouvelle politique de Santé. Analyse du cas du Quebèc, 
thèse de doctorat, Institut du Développement Economique et Social, Université de Paris/Sorbonne, 1982, 447p.

DEACON, B. - Social policy and socialism, the struggle for socialist relations of welfare, London: Pluto Press, 1983.

DESROSIERS, G. - Analyse comparée des systemes de santé, Maitrise en Santé Communautaire, Université de Montréal, Departément de Médecine Preventive et Sociale, 1980, notes de cours.

- Analyse comparée des systèmes de santé, Programme de cours, Maitrise en Santé Communautaire (MSO 6040), Université de Montréal, Departément de Médecine Preventive et Sociale, 1988.

DJUKANOVIC, V, et alie - Comment répondre aux besoins sanitaires fondamentaux des populations dans les pays en voie de développement, Genève: OMS, 1975.

ELLING, R. - Cross-national study of health systems: political economy of health care, New Brunswick/New Jersey: Transaction Books, 1982.

FIELD, M. - The concept of the health system at the macrosociological level, Social Science and Medicine, 1973, 7:763785.

FRENK, J.; DONABEDIAN, A. - State intervention in medical care: types, trends and variables, Health Policy and Planning, 1987, 2: 17-31.

FRY, J. - Medicine in three societies, London; MTP Chiltern House Aylesbury Bucks, 1969.

GARCIA, J. - Medicina y sociedad - las correntes de pensamiento en el campo de la salud, Educación Médica y Salud, 1983, 17: 363-397.

GORZ, A. - Adeus ao proletariado - para além do socialismo, Rio de Janeiro: Forense-Universitária, 1987 (2t ed.).203p.

HETZEL, B. - Basic health care in developing countries, Oxfford: Oxford University Press, 1978.

ILLICH, I. - A expropriação da saúde - nêmesis da medicina, Rio de Janeiro: Ed. Nova Fronteira, 1975.

- Duas tendências, in: Saúde da comunidade, um desafio, S. Paulo: Ed. Paulinas, 1984, p. 81-82.

KERVASDOUE, J. et alii - The end of an illusion - the future of health policy in western industrialized nations, California: University of California Press, 1984, 292p.

KLECSKOWSKI, B.; ROEMER, M.; VAN DER WERFF, A. Sistemas nacionales de salud y su reorientación hacia la salud para todos, Cuadernos de Salud Pública, n9 77, OMS, 1984.

LATHEM, W., NEWBERRY, A. - Community medicine, teaching, research and health care, New York: Appleton Century Crofts, 1970.

McKEE, J. - Holistic health and critique of western medicine, Soc. Sci. Med., 1988, 26:775-784. 
MECHANIC, D. - Future issues in health care, social policy and the relationing of medical services, New York: The Free Press, 1979.

MELLUCCI, A. - Societé en changement et nouveaux mouvements sociaux, Sociologie et societés, 1978, vol. 10, n! 2, 37-53.

MIGUEL, M. - Sociología de la medicina, una introducción crítica, Barcelona: Vicens, 1978.

MINAYO, M. C. de SOUZA - O desafio do conhecimento metodologia da Pesquisa Social (qualitativa) em Saúde, tese de doutorado, Escola Nacional de Saúde Pública/Fiocruz, 1989, $366 \mathrm{p}$.

NAVARRO, V. - Medicine under capitalism, New York: Prodest, 1976.

-_(editor) - Health and medical care in the U. S.: a critical analyses, Farmingdale, N. Y.: Baywood Publishing Company Inc., 1977.

___(comp.) - Salud e imperialismo, México, DF: Siglo Veintiuno Editores SA, 1983.

- (editor) - Health and work under capitalism: an international perspective, Farmingdale, N. Y.: Baywood Publishing Company Inc., 1983.

OMS/FISE - Les soins de santé primaire, Rapport de la Conférence Internationale sur les soins de santé primaires -Alma-Ata, 6-12 septembre 1978. Genève: 1978, pp. 2-6.

OPS - El desarrollo y fortalecimiento de los sistemas locales de salud en la transformación de los sistemas nacionales de salud, Washington, Doc. 9536c., 1988.

POSSAS, Cristina - Epidemiologia e sociedade - heterogeneidade estrutural e saúde no Brasil, S. Paulo, Ed. Hucitec, 1989, 271p.

ROEMER, M. - Perspectiva mundial de los sistemas de salud, México: Siglo Veintiuno Eds., 1980. 455p.

- Ética médica y orientación social de las enseñanzas de Medicina. Foro Mundial de la Salud, 1982 3: 405-413.

- Práctica de la medicina privada: un obstáculo en el camino de la salud para todos, Foro Mundial de la Salud, 1984, vol. 5: 227-234.

ROSTOW, W. - The stages of economic growth, Cambridge: Cambridge University Press, 1962, citado por Navarro, V. Salud e imperialismo, op. cit. pp 22-23.

SAN MARTIN, H. - Ecologia humana y salud, México: La Prensa Médica Mexicana, 1979, prólogo tradução dos autores deste artigo).

_- Crisis mundial de la salud - Salud para nadie en el año 2000?, Madrid: Ed. Ciencia 3, 1985.

STEPHEN, W. I. - An analysis of primary medical care, an international study, Cambridge: Cambridge University Press, 1979.

TERRIS, M. - Tendencias y perspectivas de los tres sistemas

Cadernos de Saúde Pública, RJ, 7(3): 328-346, ju/set, 199] 
mundiales de atención médica, Foro Mundial de la Salud, 1980, 93-103.

- Editorial - Toward a national medical care system: I Semantic problem, Journal of Public Health Policy, Summer, 1986, pp. 152-155.

- II - The historical background, Journal of Public Health Policy, Autumn, 1986, pp. 291-295.

- III - Payment to providers, Journal of Public Health Policy, Winter, 1986, pp. 431-433.

- IV - Administrative structure, Journal of Public Health Policy, Spring, 1987, pp. 7-9.

WAITZKIN, H. - A marxist view of medical care, Annals of Internal Medicine, 1978, 89: 264-278.

- The marxist paradigm in medicine, International Journal of Health Services, vol 9, $\mathrm{n}^{\mathrm{9}} 4,1979$, p. 687. 